\title{
DISFUNKCIJA SKELETNIH MIŠIĆA KOD OBOLELIH OD HRONIČNE OPSTRUKTIVNE BOLESTI PLUĆA
}

\author{
DYSFUNCTION OF SKELETAL MUSCLE IN PATIENTS WITH CHRONIC OBSTRUCTIVE \\ PULMONARY DISEASE
}

\section{Zorica Ćirić, Milan Radović, Nemanja Ćirić, Ivana Stanković, Tatjana Pejčić, Lidija Ristić, Milan Rančić}

\begin{abstract}
SAŽETAK: Uvod: Gubitak telesne i mišićne mase sa posledičnom disfunkcijom skeletnih mišića su komorbiditeti koji se često sreću kod pacijenata sa hroničnom opstruktivnom bolešću pluća (HOBP). Disfunkcija skeletnih mišića povećava dispneju i smanjuje toleranciju napora obolelih od HOBP Cilj: utvrđivanje prisustva gubitka telesne i mišićne mase, disfunkcije skeletnih mišića obolelih od HOBP $i$ analiza u odnosu na stepen težine HOBP. Metode: ispitivano je 85 pacijenata sa stabilnom HOBP. Određivan je indeks telesne mase (BMI) i debljina kožnog nabora (TSF) za procenu uhranjenosti, a obim sredine nadlaktice (MUAC) za procenu mišićne mase. Za procenu disfunkcije skeletnih mišića korišćen je 6-minutni test hodanja (6MWT) i Borg skala i modifikovana MRC (mMRC) skala dispneje. Rezultati: vrednosti BMI, TSF i MUAC sa porastom težine HOBP su opadale bez statističke značajnosti. Sa porastom težine HOBP značajno su opadale vrednosti $6 M W T(p=0,000)$, a rasle vrednosti Borg skale pre i posle $6 M W T(p=0,000)$, kao $i$ vrednosti mMRC $(p=0,000)$. Težina bolesti u celoj grupi bolesnika imala je začajnu negativnu korelaciju sa 6MWT $(p=0,000)$ i obimom sredine nadlaktice $(p=0,033)$. Zaključak: sa povećanjem težine bolesti pacijenti sa HOBP imaju veći gubitak telesne i mišićne mase, značajno lošije tolerišu fizički napor i imaju veći stepen dispneje.
\end{abstract}

Ključne reči: hronična opstruktivna bolest pluća, indeks telesne mase, dispneja,skeletni mišići.

\section{UVOD}

Hroničnu opstruktivnu bolest pluća (HOBP) karakteriše prisustvo perzistentnih respiratornih simptoma i opstrukcije u disajnim putevima. Pušenje i izloženost štetnim česticama ili gasovima su najčešći faktori rizika nastanka HOBP. ${ }^{1}$ Inhalacija duvanskog dima i ostalih štetnih čestica i gasova dovodi do nastanka inflamacije u plućima usled koje dolazi do oštećenja plućnog tkiva i remećenja procesa reparacije. U HOBP su nađene promene $\mathrm{u}$ perifernim tkivima i organima koje su slične inflamacijskim promenama u plućima, što je ukazalo da u HOBP, pored inflamacije u plućima, postoji i sistemska inflamacija. Ona je uzrok nastanka vanplućnih sistemskih efekata čije se kliničke manifestacije označavaju kao komorbiditeti. ${ }^{1,2}$ Komorbiditeti mogu imati značajan uticaj na tok bolesti.

Gubitak telesne i mišićne mase sa posledičnom disfunkcijom skeletnih mišića su komorbiditeti koji se često sreću kod pacijenata sa HOBP. ${ }^{3}$ Takođe, skeletna muskulatura u HOBP pokazuje i morfološke promene koje se manifestuju kao remećenje proporcije tipova mišićnih vlakana, odnosno dolazi do redukcije sporokontrahujućih i porasta brzokontrahujućih vlakana. ${ }^{4}$ Usled toga nastaje poremećaj funkcije skeletnih mišića: smanjenje mišićne snage ${ }^{5}$, smanjenje izdržljivosti mišića $^{6}$ i zamor mišića. ${ }^{7}$ Disfunkcija skeletnih mišića povećava dispneju i smanjuje toleranciju napora obolelih od HOBP. ${ }^{8}$ Takođe, povećava rizik od smrtnog ishoda, nezavisno od stepena težine HOBP, starosti i pušačkog statusa. ${ }^{9}$

\section{CILJ}

Cilj rada je bio da utvrdi prisustvo gubitka telesne i mišićne mase, kao i disfunkcije skeletnih mišića obolelih od HOBP $i$ da ih analizira u odnosu na stepen težine HOBP. 


\section{METODE}

Ispitivanje je obavljeno u Klinici za plućne bolesti Knez Selo Kliničkog Centra Niš. U ispitivanju je učestvovalo 85 pacijenata ( 58 muškaraca i 27 žena) obolelih od HOBP, u stabilnoj fazi bolesti.

Testiranje plućne funkcije (spirometrija) obavljeno je na aparatu Master Lab Erich Jaeger Germany u skladu sa preporukama i standardima Evropskog respiratornog društva (ERS) i Američkog torakalnog udruženja (AST). 1,10,11 Prema kriterujumima Globalne inicijative za dijagnozu, lečenje i prevenciju hronične opstruktivne bolesti puća (GOLD) ${ }^{1}$ svi pacijenti su bili podeljeni u četiri grupe: laka, umerena, teška i veoma teška HOBP.

Procena stanja uhranjenosti rađena je antropometrijskim merenjima. Merena je težina i visina pacijenata i određivan je indeks telesne mase (Body mass index - BMI). Takođe, merena je debljina kožnog nabora (Tricipital skin fold thickness - TSF) za procenu ukupnih masti u organizmu. Merenje je rađeno instrumentom kaliperom (Skinfold Caliper Harpenden) u stojećem stavu iznad m.triceps brachii. Rezultat je izražavan u milimetrima. Obim sredine nadlaktice (Mid upper arm circumference - MUAC) određivan je radi procene mišićne mase. MUAC je meren na sredini između olekranona i akromiona leve ruke (ruka je bila savijena u laktu pod uglom od $90^{\circ}$ ) i izražavan je u centimetrima.
Modifikovana desetostepena Borg skala (Borg CR-10 scale) korišćena je za procenu dispneje $u$ miru i pri naporu, a modifikovana „Medical Research Council Dyspnea Scale" (mMRC) korišćena je za utvrđivanje inteziteta dispneje pri obavljanju uobičajenih aktivnosti. Tolerisanje fizičkog napora određivano je merenjem dužine pređenog puta nakon 6 minuta brzog hoda po ravnom (6 - minutni test hodanja - 6MWT).

Statistička analiza je urađena korišćenjem standardnih programa za obradu podataka - MS EXCEL i programskog paketa SPSS verzija 10.0. Deskriptivnom statističkom analizom prikazani su sledeći statistički parametri: aritmetička sredina, standardna devijacija i interval varijacije (min-max) $\mathrm{i}$ indeks strukture (\%).Analitičkom statističkom metodologijom izmerena je statistička značajnost međusobnih razlika frekvenci pojavljivanja određenih obeležja kod svih ispitanika i razdvojeno na grupe. Testiranja su obavljena $\chi^{2}$ testom. Poređenja srednjih vrednosti obeležja između grupa vršena su t-testom za nezavisne uzorke $\mathrm{i}$ analizom varijanse (ANOVA) sa sledbenim post hock Danetovim testom.

\section{REZULTATI}

Prosečna starost ispitanika nije bila značajno različita $\mathrm{u}$ odnosu na težinu $\mathrm{HOBP}(\mathrm{F}=0,347$; $\mathrm{p}>0,05)$, takođe ni dužina trajanja bolesti $(\mathrm{F}=2,128$; $\mathrm{p}>0,05)$ što je prikazano na tabeli 1 .

Tabela 1. Starost i trajanje bolesti u odnosu na težinu HOBP

\begin{tabular}{lcccccc}
\hline & HOBP & & & & \\
& Blaga & Umerena & Teška & Veoma teška & Ukupno & ANOVA \\
& $65,6 \pm 9,56$ & $64,2 \pm 11,46$ & $65,24 \pm 8,77$ & $62,72 \pm 9,24$ & $64,24 \pm 9,74$ & $\mathrm{~F}=0,347$ \\
Starost (god.) & $(53-79)$ & $(43-79)$ & $(47-79)$ & $(41-78)$ & $(41-79)$ & $\mathrm{p}=0,791$ \\
\hline Trajanje bolesti (god.) & $9,2 \pm 5,45$ & $15,64 \pm 9,55$ & $13,84 \pm 8,71$ & $11,24 \pm 6,35$ & $13,06 \pm 8,21$ & $\mathrm{~F}=2,128$ \\
& $(2-20)$ & $(2-36)$ & $(1-31)$ & $(3-28)$ & $(1-36)$ & $\mathrm{p}=0,103$ \\
\hline
\end{tabular}

Sa povećanjem težine bolesti prosečne vrednosti antropometrijskih parametara uhranjenosti pacijenata (BMI i TSF), kao i parametara za procenu mišićne mase (MUAC) varirale su u opsegu koji nije statistički značajan. Najmanje vrednosti parametara nađene su u veoma teškoj HOBP(tabela 2). 


\begin{tabular}{lccccc} 
& & & & \\
& Blaga & Umerena & Teška & Veoma teška & $\mathrm{p}$ \\
\hline MUAC $(\mathrm{cm})$ & $30,5 \pm 5,64$ & $27,44 \pm 8,03$ & $28,64 \pm 6,61$ & $25,4 \pm 7,4$ & $\mathrm{~F}=1,496$ \\
& $(23-39)$ & $(14-47)$ & $(14-39)$ & $(13-38)$ & $\mathrm{p}=0,222$ \\
\hline TSF $(\mathrm{mm})$ & $25,1 \pm 8,57$ & $23,64 \pm 9,62$ & $25,46 \pm 10,68$ & $23,64 \pm 10,46$ & $\mathrm{~F}=0,202$ \\
& $(12-39)$ & $(10-45)$ & $(6-44)$ & $(5-49)$ & $\mathrm{p}=0,895$ \\
\hline BMI $\left(\mathrm{kg} / \mathrm{m}^{2}\right)$ & $27,311 \pm 4,39$ & $26,028 \pm 5,77$ & $25,71 \pm 4,37$ & $23,99 \pm 5,23$ & $\mathrm{~F}=1,262$ \\
& $(21,5-35,36)$ & $(18,4-40,4)$ & $(19-32,9)$ & $(15,04-34,6)$ & $\mathrm{p}=0,293$ \\
\hline
\end{tabular}

Sa povećanjem težine bolesti povećavala se disfunkcija skeletnih mišića, tačnije prosečne vrednosti 6MWT značajno su opadale dok su vrednosti parametara dispneje (mMRC, Borg, $\Delta$
Borg $=$ Borg pre $6 \mathrm{MWT}-$ Borg posle $6 \mathrm{MWT}$ ) značajno rasle (tabela 3 ).

Tabela 3. 6MWT, Borg skor, $m M R C$ i težina HOBP

\begin{tabular}{|c|c|c|c|c|c|}
\hline & $\frac{\text { HOBP }}{\text { Blaga }}$ & Umerena & Teška & Veoma teška & $\begin{array}{c}\text { ANOVA } \\
p\end{array}$ \\
\hline 6MWT & $\begin{array}{r}486 \pm 31,69 \\
(450-540) \\
\end{array}$ & $\begin{array}{c}397,6 \pm 55,77 \\
(340-540) \\
\end{array}$ & $\begin{array}{c}322 \pm 86,64 \\
(210-540)\end{array}$ & $\begin{array}{c}229,2 \pm 77,82 \\
(60-360)\end{array}$ & $\begin{array}{c}\mathrm{F}=40,246 \\
\mathrm{p}=0,000\end{array}$ \\
\hline Borg pre $6 \mathrm{MWT}$ & $\begin{array}{r}0 \pm 0 \\
(0-0) \\
\end{array}$ & $\begin{array}{c}0,12 \pm 0,33 \\
(0-1) \\
\end{array}$ & $\begin{array}{c}0,76 \pm 0,88 \\
(0-3)\end{array}$ & $\begin{array}{c}2,76 \pm 2,24 \\
(0-9)\end{array}$ & $\begin{array}{c}F=20,535 \\
p=0,000\end{array}$ \\
\hline Borg posle 6MWT & $\begin{array}{c}0 \pm 0 \\
(0-0) \\
\end{array}$ & $\begin{array}{c}0,6 \pm 0,71 \\
(0-2) \\
\end{array}$ & $\begin{array}{c}1,72 \pm 1,17 \\
(0-5)\end{array}$ & $\begin{array}{c}4,36 \pm 2,2 \\
(1-10) \\
\end{array}$ & $\begin{array}{c}F=38,635 \\
p=0,000\end{array}$ \\
\hline$\Delta$ Borg & $\begin{array}{c}0 \pm 0 \\
(0-0) \\
\end{array}$ & $\begin{array}{c}0,48 \pm 0,51 \\
(0-1) \\
\end{array}$ & $\begin{array}{c}0,96 \pm 0,54 \\
(0-2)\end{array}$ & $\begin{array}{c}1,6 \pm 0,58 \\
(1-3)\end{array}$ & $\begin{array}{c}\mathrm{F}=31,645 \\
\mathrm{p}=0,000\end{array}$ \\
\hline$\overline{\mathrm{mMRC}}$ & $\begin{array}{c}0 \pm 0 \\
(0-0)\end{array}$ & $\begin{array}{c}0,28 \pm 0,46 \\
(0-1)\end{array}$ & $\begin{array}{c}0,88 \pm 0,83 \\
(0-3)\end{array}$ & $\begin{array}{c}2,48 \pm 1,12 \\
(1-4)\end{array}$ & $\begin{array}{c}\mathrm{F}=40,384 \\
\mathrm{p}=0,000\end{array}$ \\
\hline
\end{tabular}

Urađena je korelacija dobijenih rezultata Pirsonovim testom (Pearson correlation) za parametrijske uzorke i Spirmanovim testom (Spearman's correlation) za neparametrijske uzorke. Našli smo da je težina bolesti u celoj grupi bolesnika imala začajnu negativnu korelaciju sa 6MWT $(\mathrm{p}=0,000)$ i obimom nadlaktice (MUAC: $\mathrm{p}=0,033)$.

\section{DISKUSIJA}

Hroničnu opstruktivnu bolest pluća odlikuje hronična inflamacija u plućima čiji se intezitet povećava sa progresijom bolesti. ${ }^{1,12}$. Veći broj studija pokazao je da su u HOBP povećane vrednosti više inflamatornih medijatora kao što je Creaktivni protein (CRP), hemotaktičnih medijatora (leukotrien $\mathrm{B}_{4}-\mathrm{LTB}_{4}$; interleukin 8 - IL-8) kao i proinflamatornih citokina (interleukin 6 - IL-6; faktor nekroze tumora alfa - TNF- $\alpha$ ) koji pojačavaju inflamatornu reakciju. Isto tako su povećane vrednosti faktora rasta (transformišući faktor rasta beta- TGF $\beta$ ) koji su odgovorni za strukturne promene $u$ plućima (fibroza malih disajnih puteva). ${ }^{13,14}$ Oksidativni stres je važan mehanizam nastanka i pojačavanja inflamatornog odgovora $\mathrm{u}$
HOBP. ${ }^{1}$ Povećanje inflamatornih medijatora u krvi obolelih od HOBP ukazuje da pored inflamacije u plućima postoji i sistemska inflamacija niskog stepena, ali za sada još uvek nema sigurnih dokaza koji su mehanizmi njenog nastanka. Smatra se da je sistemska inflamacija uzrok nastanka vanplućnih manifestacija HOBP.

Gubitak telesne mase može se naći kod 20-40\% pacijenata sa HOBP. ${ }^{15}$ Telesna masa zavisi od količine masti (fat mass - FM), nemasne mase tela (fat free mass - FFM) i ukupnog sadržaja vode $u$ organizmu. ${ }^{16}$ FFM se definiše kao deo telesne mase bez potkožnog masnog tkiva. Metabolički aktivno tkivo (organi) i kontraktilno tkivo (mišići) su primer FFM. Smanjenje FFM ukazuje na smanjenje mišićne mase. ${ }^{16}$ Pored sistemske inflamacije, kao potencijalni mehanizmi nastanka gubitka telesne mase u HOBP navode se još energetski disbalans, hipoksemija i hormonska insuficijencija. ${ }^{17}$

Određivanje BMI se koristi za procenu gubitka telesne mase i stanja uhranjenosti. Kod HOBP pacijenata gubitak telesne mase uglavnom nastaje zbog smanjenja mišićne mase (FFM), mada pothranjeni HOBP pacijenti u najvećem broju slučajeva imaju gubljenje FFM sa istovremenim gubljenjem i FM. $^{18}$ Za procenu FM koristi se 
merenje debljine kožnog nabora (TSF). Merenje obima nadlaktice (MUAC) ukazuje na razvijenost mišićne mase i veličinu FFM s obzirom da mišići čine $60-80 \%$ FFM. $^{19} \mathrm{~S}$ toga se merenje MUAC koriste za procenu gubitka mišićne mase, ali isto tako i za procenu gubitka telesne mase koja nastaje pretežno usled gubitka mišićne mase. Analizom vrednosti antropometrijskih parametara naših pacijenata našli smo da su sa povećanjem težine HOBP prosečne vrednosti BMI, MUAC i TSF opadale, ali u opsegu koji nije statistički značajan. Najveće vrednosti BMI, MUAC i TSF našli smo u grupi sa lakom HOBP, a najmanje u grupi sa veoma teškom HOBP što je ukazivalo da pacijenti sa teškom HOBP imaju najveći gubitak telesne i mišićne mase. Podaci iz literature navode da je gubitak mišićne mase kao i gubitak telesne mase $\mathrm{i}$ nastanak pothranjenosti češći kod bolesnika sa teškom HOBP. ${ }^{15}$ Takođe, i da gubitak telesne mase nastaje uglavnom zbog gubitka mišićne mase, mada istovremeno postoji $\mathrm{i}$ gubitak $\mathrm{FM}^{18}$ što su $\mathrm{i}$ naši rezultati pokazali, tako da su oni u saglasnosti sa podacima iz literature.

Istovremeno sa smanjenjem mase skeletnih mišića u njima se dešavaju i strukturne promene koje su uzrok nastanka funkcionalnih poremećaja skeletnih mišića HOBP pacijenata. ${ }^{20}$ Apoptoza mišićnih ćelija i atrofija mišićnih vlakana su odgovorni za smanjenje snage mišića, ${ }^{21}$ a povećanje Tip II mišićnih vlakana i smanjenje oksidativnog kapaciteta smanjuju izdržljivost i povećavaju zamor mišića. $^{21}$ Tako nastali funkcionalni poremećaji mišića klinički se manifestuju smanjenjem podnošenja fizičkog napora ${ }^{22}$ i povećanjem intenziteta dispneje. ${ }^{21}$. Stepen smanjenja snage skeletnih mišića, pre svega ekstremiteta, koreliše sa stepenom težine HOBP i kod bolesnika sa teškom HOBP značajan je prediktor mortaliteta. ${ }^{21}$

Analizirali smo izraženost disfunkcije skeletnih mišića naših ispitanika kroz analizu njihovog funkcionalnog statusa i kapaciteta. Koristili smo 6MWT koji pokazuje koliki intenzitet uobičajenih dnevnih aktivnosti ispitanik može da toleriše. ${ }^{23} \mathrm{~S}$ druge strane mMRS skala dispneje pokazuje nivo aktivnosti koji dovodi do dispneje i ukazuje koliko je nivo onesposobljenosti pacijenta za obavljanje dnevnih aktivnosti usled dispneje, dok se Borg skala koristi za određivanje stepena dispneje. ${ }^{24}$ Kada se Borg skala koristi pre i posle 6MWT promena njenog skora pokazuje promenu stepena dispneje pri opterećenju i služi za procenu zamora. $^{24,25}$ Zbog svega navedenog 6MWT, mMRC i Borg skala su dosta dobri pokazatelji funkcionalnog stanja i kapaciteta HOBP bolesnika.

Disfunkcija skeletnih mišića naših ispitanika povećavala se sa porastom težine HOBP tako da su oni imali značajno smanjenje funkcionalnog kapaciteta. Sa povećanjem težine HOBP ispitanici su imali značajno smanjenje tolerancije napora, opadanje prosečnih vrednosti 6MWT uz istovremeno značajno veći intenzitet dispneje i onesposobljenost za obavljanje dnevnih aktivnosti (porast skora mMRC i Borg skale). Utvrdili smo da postoji značajna negativna korelacija težine HOBP i 6MWT i da postoji značajna negativna korelacija tolerancije napora $\mathrm{i}$ intenziteta dispneje (6MWT i mMRC; 6MWT i Borg skala) kao i značajna pozitivna korelacija skala za procenu intenziteta dispnoje što je saglasno podacima iz literature..$^{21,22,23}$

\section{ZAKLJUČAK}

Rezultati našeg istraživanja pokazali su da oboleli od HOBP imaju gubitak telesne i mišićne mase usled čega dolazi do disfunkcije skeletnih mišića. Sa povećanjem težine bolesti pacijenti su značajno lošije tolerisali fizički napor i imali veći stepen dispneje.

\section{LITERATURA}

1. Global Initiative For Chronic Obstructive Lung Disease (GOLD). Global strategy for the diagnosis, management, and prevention of chronic obstructive pulmonary disease. (2017 Report) http//www.goldcopd.org. Accessed November 29, 2016.

2. Barnes PJ. Inflammatory mechanisms in patients with chronic obstructive pulmonary disease. J Allergy Clin Immunol 2016:138(1);16-27.

3. Wagner PD. Possible mechanisms underlying the development of cachexia in COPD. Eur Respir J 2008;31:492-501.

4. Gosker HR, van Mameren H, van Dijk PJ, et al. Skeletal muscle fiber-type shifting and metabolic profile in patients with chronic obstructive pulmonary disease, Eur Respir J 2002; 19:617-625.

5. Engelen MP, Schols AM, Does JD, Wouters EF. Skeletal muscle weakness is associated with wasting of extremity fat-free mass but not with airflow obstruction in patients with chronic obstructive pulmonary disease. Am J Nutr 2000; 71: 733-738. 
6. Van’t Hul A, Harlaar J, Gosselnik R, Hollander P, Postmus P, Kwakkel G. Quadriceps muscle endurance in patients with chronic obstructive pulmonary disease. Muscle Nerve 2004; 29:267-274.

7. Jeffery Mador MJ, Kufel TJ, Pineda L. Quadriceps fatigue after cycle exercise in patients with chronic obstructive disease. Am J respir Crit Care Med 2000;161:447-453.

8. Jones NL, Killian KJ. Mechanisms of disease: Exercise limitation in health and disease. N Engl $\mathrm{J}$ Med 2000; 343: 632-641.

9. Marquis $\mathrm{K}$, et al. Midthigh muscle cross-sectional area is better predictor of mortality than body mass index in patients with chronic obstructive pulmonary disease. Am J Respir Crit Care Med 2002; 166:809813.

10. Pellegrino R, Viegi G, Brusasco V, Crapo R.O., Burgos F, Casaburi R, et al. Interpretative strategies for lung function tests. Eur Respir J 2005;26:948968.

11. Standardisation of spirometry. Eur Respir J 2005;26: 319-338.

12. Stanković, Pejčić T. Patofiziologija hronične opstruktivne bolesti pluća. U: Bošnjak-Petrović V, ed. Hronična opstruktivna bolest pluća. Beograd: Klinički Centar Srbije, Beograd, 2004:29-35.

13. Milenković B. Inflamacija u hroničnoj opstruktivnoj bolesti pluća. U: Stanković I, ed. Savremena saznanja o hroničnoj opstruktivnoj bolesti pluća. Niš: Medicinski fakultet Univerziteta u Nišu, 2012:24-29.

14. PintoPlata VM, Mullerova H, Toso JF, Feudjo-Tepie $\mathrm{M}$, Soriano JB,Celli BR. C-reactive protein in patients with COPD, control smokers and non smokers. Thorax 2006;61(1):23-28.

15. Wagner PD. Possible mechanisms underlying the development of cachexia in COPD. Eur Respir J 2008;31:492-501
16. Nikolić M. Održavanje telesne mase. U Nikolić M, urednik. Dijetetika. Niš: Medicinski fakultet Univerziteta u Nišu\&WUS Austria; 2008. s.115131.(srpski)

17. Zvezdin B. Hronična opstruktivna bolest pluća i komorbiditet. U: Stanković I, ed. Savremena saznanja o hroničnoj opstruktivnoj bolesti pluća. Niš: Medicinski fakultet Univerziteta u Nišu, 2012:82-86.

18. Liu X, Ji Y, Chen J, Li S, Luo F. Circulating visfatin in chronic obstructive pulmonary disease. Nutrition 2009; 25(4):373-378.

19. Powell-Tuck J, Hennessy E.M. A comparison of mid upper arm circumference, body mass index and weight loss as indices of undernutrition in acutely hospitalized patients. Clinical Nutrition 2003; 22(3):1-6.

20. Gosker HR, van Mameren H, van Dijk PJ, et al. Skeletal muscle fiber-type shifting and metabolic profile in patients with chronic obstructive pulmonary disease, Eur Respir J 2002; 19:617-625.

21. Gosker HR, van Mameren H, van Dijk PJ, et al. Skeletal muscle fiber-type shifting and metabolic profile in patients with chronic obstructive pulmonary disease, Eur Respir J 2002; 19:617-625.

22. Debigare R, Maltais F. The major limitation to exercise performance in COPD is lower limb muscle dysfunction. J Appl Physiol 2008; 105:751-753.

23. Criner G. 6-minute walk testing in COPD: is it reproducible? Eur Respir J 2011;38:244-245.

24. Hernandes NA, Wouters EFM, Meijer K, Annegarn J, Pitta F, Spruit MA: Reproducibility of 6-minute walking test in patients with COPD. Eur Respir J 2011; 38: 261-267.

25. ATS Statement: Guidelines for the Six-Minute Walk Test. Am J Respir Crit Care 2002;166: 111-117.

ABSTRACT: Introduction: The weight loss and muscle mass loss with consequent dysfunction of skeletal muscle are comorbidities that are frequently found in patients with chronic obstructive pulmonary disease (COPD). Dysfunction of skeletal muscles increases dyspnea and reduces exercise tolerance in patients with COPD Aim: determining the presence of weight loss and muscle mass loss, skeletal muscle dysfunction in patients with COPD, and the analysis in relation to the degree of COPD severity. Methods: 85 patients with stabile COPD were analyzed. The assessment of nutritional status was determined by body mass index (BMI) and skinfold thickness (TSF), and mid-upper arm circumference (MUAC) was used for assessment of muscle mass. For the assessment of dysfunction of skeletal muscles a 6-minute wallking test (6MWT), Borg scale and modified MRC (mMRC) scale of dyspnea were used. Results: BMI levels, MUAC and TSF decreased without statistical significance with increasing COPD severity. With the increase in COPD severity $6 M W T$ significantly declined $(p=0.000)$, and Borg scale values before and after the 6MWT increased $(p=0.000)$, as well as the values of $m M R C$ $(p=0.000)$. Severity of the disease in the whole group of patients had a significant negative correlation 
with the 6MWT $(p=0.000)$ and MUAC $(p=0.033)$. Conclusion: with the increasing severity of the disease, patients with COPD have a higher weight loss and muscle mass loss, tolerate physical effort significantly worse and have a higher degree of dyspnea.

Key words: chronic obstructive pulmonary disease, body mass index, dyspnea, skeletal muscles.

\section{Zorica Ćirić}

18000 Niš, Srbija. Uroša Predića 4/25

Tel: +381631703489

e-mail: zorica_ciric@yahoo.com 